\title{
Controlled Growth and Applications of Carbon Nanotubes
}

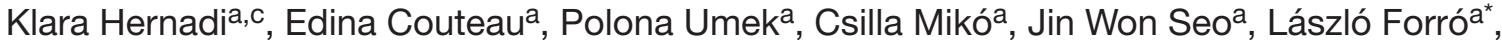 \\ Mirko Croci ${ }^{\mathrm{b}}$, Christian Klinke ${ }^{\mathrm{b}}$, Pauline Chauvin ${ }^{\mathrm{b}}$, and Jean-Marc Bonard ${ }^{\mathrm{b}, \mathrm{d}, \mathrm{e}}$
}

\begin{abstract}
This article reviews recent results in the field of nanotube research obtained at EPFL. We show in particular that with catalytic deposition techniques such as chemical vapor deposition carbon nanotubes with controlled properties can be obtained. We then discuss the functionalization of these CVD-grown nanotubes for the realization of fibers and composites, as well as their use in field emission devices.
\end{abstract}

Keywords: Carbon nanotubes - Chemical vapor deposition - Composites · Field emission · Functionalization

\section{Introduction}

As the number of academic and industrial scientists involved in carbon nanotube research [1] steadily increases, and therewith the demonstrations for their application in various fields, it is becoming increasingly apparent that one of the keys to a successful use of these nanostructures is the control of the growth, be it for mechanical strengthening, electronic devices, chemically functionalized structures or field emitters. During the first years of nanotube research, nanotubes were mostly produced by arc discharge or laser ablation. Recent developments in chemical vapor deposition (CVD) have rendered the catalytic techniques, where a hydrocarbon gas is decomposed over a transition metal catalyst to grow nanotubes, increasingly attractive. We present here some recent examples of advances in the field of carbon nanotube growth by

${ }^{*}$ Correspondence: Dr. L. Forróa

Tel.: +41216934306

Fax: +41216934470

E-Mail: laszlo.forro@epfl.ch

www.nanotubes.epfl.ch/forro/

anstitut de Physique de la Matière Complexe

Faculté des Sciences de Base, EPFL

$\mathrm{CH}-1015$ Lausanne

bInstitut de Physique des Nanostructures

Faculté des Sciences de Base, EPFL

$\mathrm{CH}-1015$ Lausanne

cPermanent address: Applied Chemistry

and Environment Department

József Attila University, H-6720 Szeged, Hungary

dPresent address: Rolex S.A.,

3-7 rue François-Dussaud

$\mathrm{CH}-1227$ Les Acacias-Genève

ehttp://ipnwww.epfl.ch/nanotubes.html
CVD and subsequent functionalization, incorporation in composites, and use in field emission devices.

\section{Catalytic Growth}

Carbon filaments and fibers have been produced by thermal decomposition of hydrocarbons since the 1960s [2]. Such fibers were either amorphous in nature, and had to be subsequently graphitized by heat treatment [3], or were partly graphitized in a herring-bone pattern [4]. A similar approach was used for the first time in 1993 to grow multiwall nanotubes (MWNTs) from the decomposition of acetylene over iron particles [5]. In nanotube CVD, the growth proceeds by the decomposition of the gaseous carbon source (typically $\mathrm{CH}_{4}$ or $\mathrm{C}_{2} \mathrm{H}_{2}$ ) at the surface of the catalyst particle (typically $\mathrm{Fe}, \mathrm{Ni}$, Co or their oxides). The carbon is then dissolved in and diffuses through the particle, until supersaturation is reached and carbon is segregated in a sp2 structure to avoid dangling bonds, which ultimately leads to the formation of a nanotube.

The catalytic method has undergone dramatic improvements in the last few years [6-8], using in a first phase silica [9] and zeolites as catalyst supports [10][11]. The CVD methods are also ideally suited to grow films of nanotubes on substrates such as silicon [12-16] or glass [17][18]. In many cases, there are no or very few codeposited carbon allotropes. Cumbersome purification steps are thus unnecessary. Substrates can be directly patterned with catalysts using lithographic techniques.

Several CVD techniques have been demonstrated in the past years. The thermal CVD is a simple pyrolysis, usually performed in a flow reactor inside a tubular oven as shown in Fig. 1a. The CVD process can also be assisted by a hot filament (hot filament CVD) [19], and/or by a microwave or rf plasma (plasma enhanced CVD) [17][20]. The latter two embodiments are more complicated but allow significant decrease of the growth temperature and more flexible adjustment of the reaction atmosphere [21]. Instead of heating reaction gas and substrate in a flow reactor, one can also heat only the catalyst-covered substrate, as in Fig. 1b, which offers the possibility of growing carbon nanotubes on long substrates.

Clearly, both placement and diameter of the nanotube depend on the catalyst particle as the growth is activated by the catalyst. The formation of the catalyst particles is therefore a crucial step of the growth, as each nano-sized particle will ideally lead to the catalytic growth of only one nanotube. One possibility to form the catalyst particles needed to seed the growth of nanotubes is to start from metallic ions dissolved in a solution. The particles form from the individual ions by aging in the solution or coalescence during high temperature annealing [22].

This approach allows one also to realize nanotube patterns on a substrate, as shown 


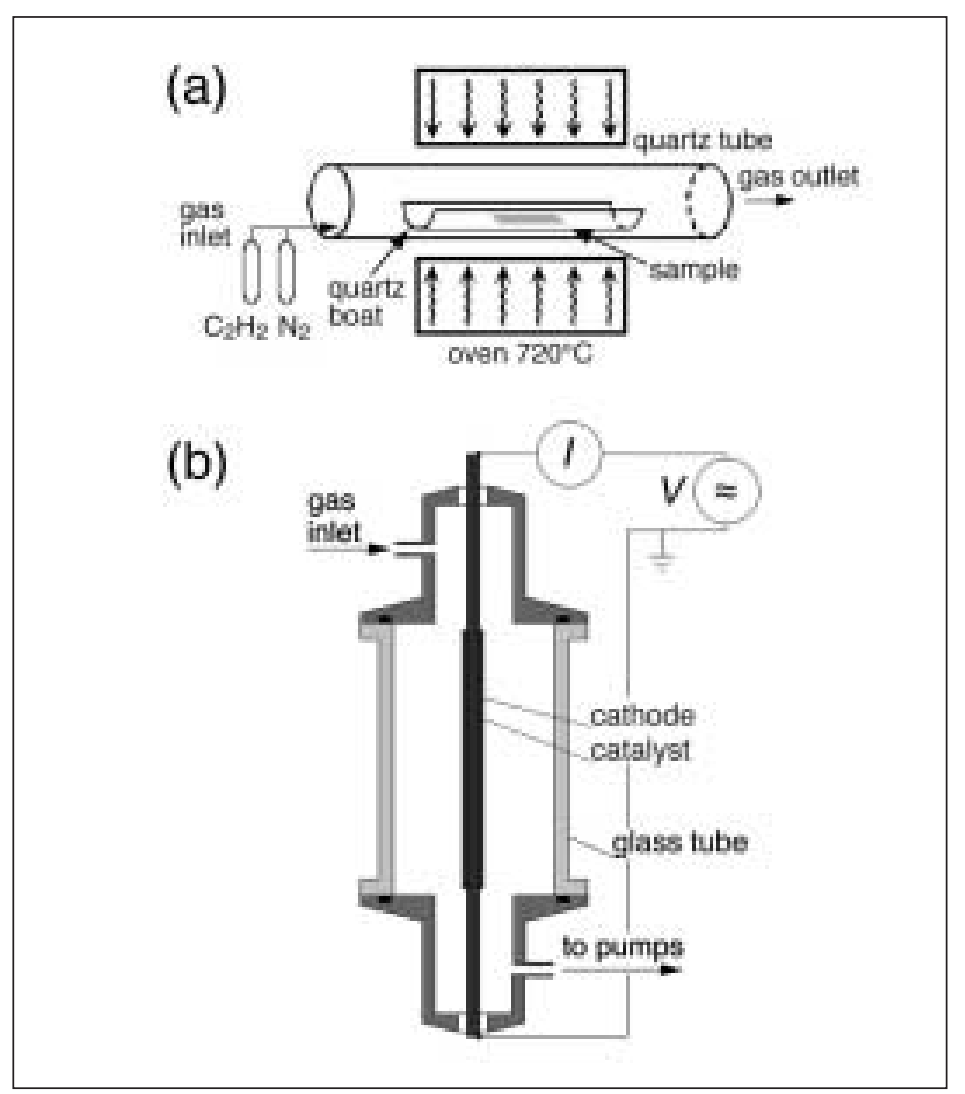

in Fig. 2. As the catalyst precursor is a liquid solution, standard lithography techniques cannot be used. Conversely, soft lithography, a nonphotolithographic technique developed in 1993 by Whitesides [23] and where a patterned elastomer is used to deliver a material onto a surface, is compatible with many liquid phase catalyst precursors. For the patterned growth of nanotubes, microcontact printing $(\mu \mathrm{CP}$, which is one variation of soft lithography) of catalyst precursors has been successfully implemented as schematized in Fig. 2a [15][24]. The structured stamp, obtained by curing an elastomer over photoresist patterns defined on a Si wafer (the 'master'), is loaded with a catalyst solution (the 'ink'). The catalyst is then transferred onto the substrate by mechanical contact [15]. Singlewall nanotubes (SWNTs) or MWNTs can be grown on the pattern of catalyst depending on the combination of catalyst precursor, hydrocarbon gas and deposition temperature. An example of such regular patterning is shown in Fig. 2b, for MWNTs grown by hot filament CVD of $\mathrm{CH}_{4}: \mathrm{H}_{2}$ at $570{ }^{\circ} \mathrm{C}$ over mixed Al:Fe catalysts [25][26].

The use of a liquid catalyst allows great flexibility. Since the ink is a solution, one can vary the composition and concentration of dissolved transition metal salts, which is of crucial importance to control the growth. For example, the density of nanotubes can be varied with the initial concentration of metallic ions in the solution [22]. For low concentrations of iron nitrate in ethanol
Fig. 1. Schematics of different CVD production techniques: (a) usual thermal CVD, where the gas is decomposed in a flow reactor that crosses the hot zone of an oven; (b) cold atmosphere CVD, where only the substrate is resistively heated.
(1 mM) only a few single nanotubes are distributed randomly over the printed zones. Increasing the concentration of the catalyst to 20 and $40 \mathrm{mM}$ leads to the formation of a film of entangled nanotubes. Finally, a concentration around $50 \mathrm{mM}$ results in very dense arrays of nanotubes aligned perpendicular to the surface. For concentrations higher than $60 \mathrm{mM}$, the growth of nanotubes is almost inhibited and the pattern is decorated by carbon particles. A sparse growth of nanotubes (instead of thick mats) can be realized with a mixed catalyst, where the active catalyst is dispersed in an inert matrix as has been demonstrated by combining iron nitrate with aluminum nitrate [27].

The nanotube diameter is more difficult to adjust, but monodisperse particles suspended in solution can also be delivered by microcontact printing if a monodisperse growth is needed. The power of this approach has been demonstrated by using the iron-containing cores of ferritin as catalyst [28]. The key to the use of such particles is to avoid their coalescence at the growth temperature, which can be done by immobilizing or embedding them in a matrix that is both stable at the growth temperature and inert for the CVD growth. Aluminum nitrate was successfully used as an additive to grow carbon nanotubes with an outer diameter of $5.2 \pm 0.6 \mathrm{~nm}$.

It is also desirable for some applications to deposit carbon nanotubes on nonplanar substrates such as wires or rods. Basically,

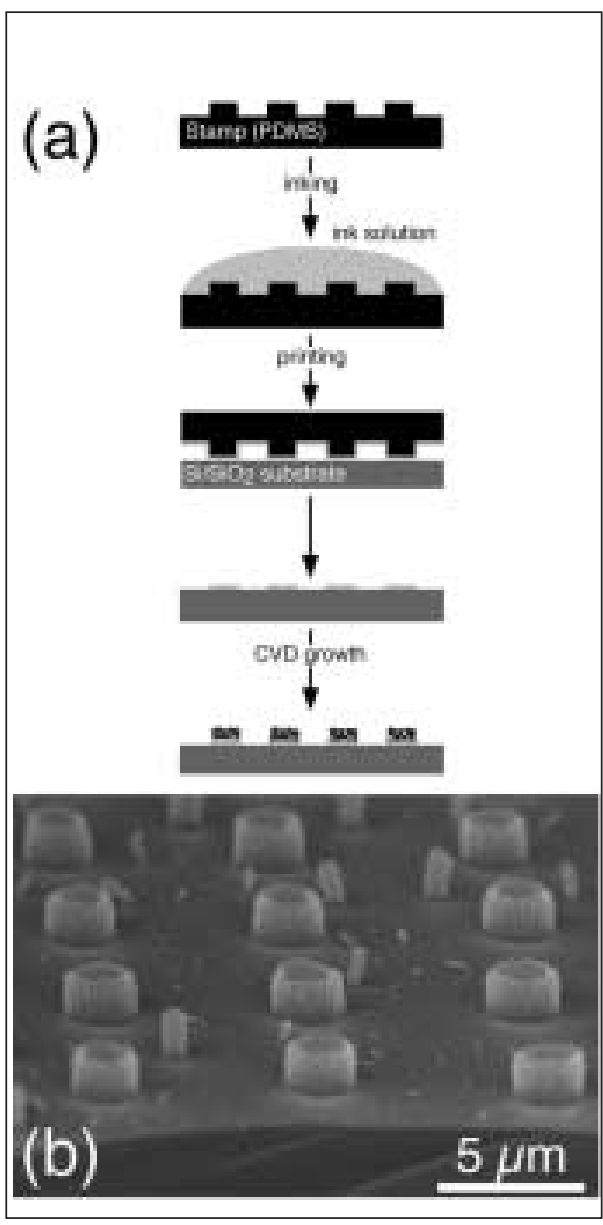

Fig. 2. Patterns of catalysts realized by microcontact printing: (a) schematics of the patterning procedure; (b) nanotube patterns ('bowls') grown by hot filament CVD of $\mathrm{CH}_{4}: \mathrm{H}_{2}$ at $570{ }^{\circ} \mathrm{C}$ over mixed Al:Fe catalysts. 
nothing prevents the CVD growth of nanotubes on non-planar substrates: the only condition is that the substrate is uniformly heated. This is naturally realized in a flow reactor, and thermal CVD is for this the most practical implementation [29][30]. However, the usual CVD methods become impractical for deposition over large substrates (e.g. to realize the $40 \mathrm{~cm}$-long cathode, consisting of nanotubes deposited on a thin wire, of the luminescent tube presented in Fig. 6), as the entire substrate has to be uniformly heated in the hot zone of the oven.

One possibility to avoid this problem is shown in Fig. 1b, and consists in heating only the substrate by resistive heating instead of placing the substrate in the hot zone of an oven. In that case, the growth is carried out under a partial pressure of acetylene (1-400 mbar) with the glass tube as reactor enclosure. As only a very small volume of gas is heated to the reaction temperature, we have named this method 'cold atmosphere chemical vapor deposition', or CACVD [31]. Besides making possible the deposition of nanotubes on large substrates, CACVD allows the morphology of the nanotube film (density and length of the nanotubes) to be influenced by reaction temperature and gas pressure, which is a precious advantage for the realization of field emission devices [32].

\section{Functionalization}

One of the main interests in carbon nanotube research is to develop novel materials which incorporate the unique physical properties of carbon nanotubes. A representative example of this effort is to assemble carbon nanotubes into long macroscopic fibers. For this process, nanotubes are dispersed in a surfactant solution, re-condensed into fibers, and pulled out from the dispersion by applying an inhomogeneous electric field [33]. As can be seen in the scanning electron microscopy (SEM) micrograph (Fig. 3), the rope with a diameter about $10 \mu \mathrm{m}$ exhibits nanotube bundles with a preferential alignment along the fiber axis. The mechanical strength of the prepared ropes is not as high as expected, which can be explained by the weak interaction between the individual nanotubes and bundles within the rope. By chemical modification of the carbon nanotubes, the

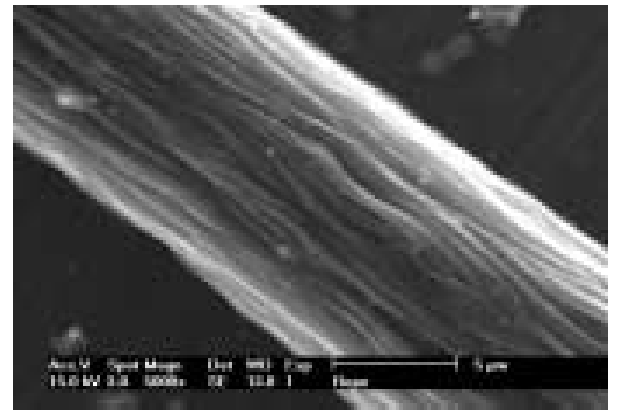

Fig. 3. SEM image of a representative SWNT rope with homogeneously well-oriented bundles of SWNTs. The diameter of the rope is about $10 \mu \mathrm{m}$.

cross-linking between separate bundles can be improved and the strength of the ropes is expected to be considerably enhanced.

The chemical reactivity of CNTs lies between that of fullerenes and graphite, and strongly depends on the diameter of the nanotubes [34]. Beside the low reactivity, the very low solubility or dispersibility of CNTs in organic solvents makes their functionalization very difficult. Therefore, sidewall functionalization by forming covalent bonds can be only achieved with highly reactive reagents [35]. In our laboratory, the investigation of functionalization of SWNTs is concentrated along two main approaches. The first approach is 'spin labeling', where functional groups are attached to SWNT sidewalls via $\mathrm{S}-\mathrm{S}$ bridges. Their density can be directly measured by the electron spin resonance technique. The second approach is the sidewall functionalization of SWNTs with carbon radicals. Radical addition to alkenes is a topic of great interest in the fields of radical polymerization, organic synthesis, combustion and atmospheric chemistry [36]. As a source of carbon radicals, lauroyl peroxide and dibenzoyl peroxide were used. These kind of peroxides thermally decompose to $\mathrm{CH}_{3}\left(\mathrm{CH}_{2}\right)_{10} \cdot$ and phenyl radicals. The side product of thermal decomposition of dialkyl and diaroyl peroxides is $\mathrm{CO}_{2}$.

Fig. 4 shows sections of FT-IR spectra obtained for lauroyl peroxide (LP), initial SWNTs, and the SWNT material after the reaction with LP. The direct comparison of FT-IR spectra of SWNTs before and after radical addition shows that a new band appears between $2800-3000 \mathrm{~cm}^{-1}$. This band is also found in the spectrum of LP and corresponds to the stretching of $\mathrm{CH}$ bonds in the alkyl chain of LP. Therefore, the presence of this band in the spectrum of our functionalized SWNT material is clear evidence for the successful sidewall functionalization of SWNTs. In general, functionalization of SWNTs by radical addition is a relatively simple and also an efficient technique for attaching alkyl or aryl groups onto the sidewalls of SWNTs. Therefore it is one of the most promising functionalization techniques so far. Moreover, functionalization with alkyl or aryl chains will allow additional insertion of different functional groups onto these chains. Hence, this approach will enable adjustable modification of the chemical properties of SWNTs with respect to the applications.
Fig. 4. FT-IR spectra between 3300 and $2700 \mathrm{~cm}^{-1}$ of lauroyl peroxide, SWNT raw material, and SWNT material after the reaction with lauroyl peroxide.

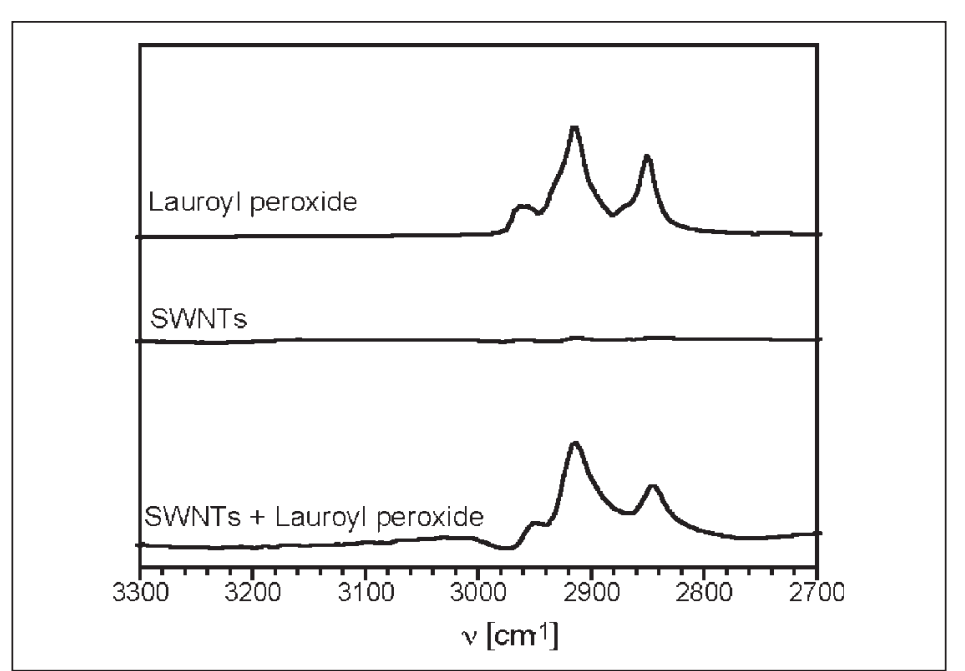




\section{Composites}

Composites based on carbon fibers coated with polymer and/or ceramic have found various applications historically [37]. When the fibers are substituted by carbon nanotubes, composites with unique mechanical properties are expected, which can also provide many other applications due to the extraordinary optical and electrical properties mentioned above. Examples can be found $e . g$. in electronic devices used in batteries and sensors [38-40]. A large variety of possible composite materials using single-walled carbon nanotubes and MWNTs combined either with different polymers [41-43] or with organic compounds have been prepared so far [44-50]. In particular, composites with a metal matrix reinforced with carbon nanotubes are expected to have unique mechanical properties [51]. By the formation of metal- or polymer-based composites, two major obstacles have to be overcome in order to obtain a proper coating on the surface of carbon nanotubes: (i) the wettability of the carbon nanotube surface and (ii) the load transfer from the matrix to the nanotubes. Therefore, the nanotube surface has to be 'clean' and in particular free of amorphous carbon at the initial stage of composite preparation, since amorphous carbon can affect or even hinder the interaction between the nanotube surface and the coverage material. Recently, we succeeded in producing MWNTs with a homogeneous coverage of various inorganic materials, such as alumina, silica and titania [52][53]. For the preparation, MWNTs were synthesized by catalytic CVD with a $5 \%$ $\mathrm{Co}, \mathrm{Fe} / \mathrm{CaCO}_{3}$ catalyst and purified with a newly developed purification method [54]. Subsequently, composites were prepared by impregnation of organometallic and inorganic compounds as precursors. Our results suggest that an effective interfacial bonding between carbon nanotube surface and precursors is the most important issue for the formation of MWNT-based composites. In particular, the ionic character of the coating material has to be taken into account. In the case of 'raw' MWNTs, impregnation with organometallic and nonionic inorganic compounds was successful, whereas any treatment of MWNTs with ionic surfactants was unfavorable for composite formation. With ionic coatings such as $\mathrm{AlCl}_{3}$, the adsorbed layer of surfactant promotes the coverage via ionic interaction and, as can be seen in Fig. 5b, a homogeneous coverage of amorphous alumina can be obtained with a thickness of about $3 \mathrm{~nm}$. Moreover, the sample is free of segregation of precursor materials (Fig. 5a) and indi-

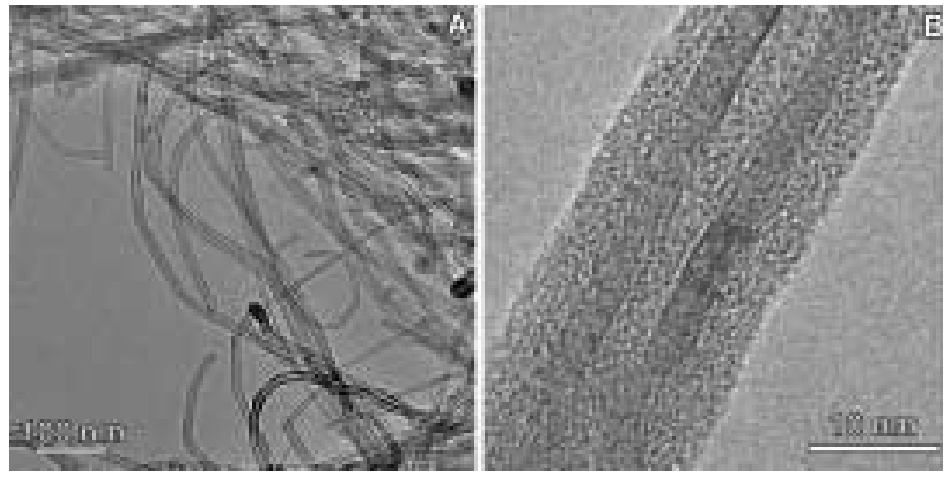

Fig. 5. Transmission electron microscopy (TEM) images of alumina/ MWNT composite materials at (a) low magnification and (b) high resolution. The sample is free of segregation of alumina. The MWNTs are homogeneously covered with an amorphous alumina layer with a thickness of about $3 \mathrm{~nm}$.

cates that the interaction between the nanotubes and the coating material is the most predominant reaction.

\section{Field Emission Devices}

Field emission is one of the most promising applications for carbon nanotubes [55]. The feasibility of cold electron emission from nanotube and nanotube arrays was demonstrated in 1995 [56][57]. The potential to use nanotubes as field emission devices spurred efforts worldwide from 1998 on, when a first display as well as a lighting element were presented. Various devices as varied as single coherent electrons sources for advanced microscopy [58], high brightness luminescent elements [59], gas discharge tubes [60], microwave tubes [61] and flat panel displays [62][63] have been demonstrated. One commercial product incorporating a nanotube field emission cathode, Oxford Instruments' Horizon 600 portable X-Ray spectrometer, has been commercially available since the beginning of the year in the USA [64].

Although flat panel displays catch most of the limelight as they represent the largest potential market, simpler devices are currently under active investigation, especially for lighting applications. Field emitters can be used to produce light by bombarding a phosphor-coated surface with electrons. As an example, we have realized mercury-free tubular elements based on the principle depicted in Fig. 6a. Nanotubes are deposited by CVD on a wire that is placed in the center of a glass tube. Electrons are emitted by applying a potential difference between the nanotubes and the conductive-plus-phosphor layer that covers the inner surface of the glass tube, and produce light by bombarding the phosphor layer. To ensure a uni- form light emission from the phosphor, the cathode itself must be cylindrical, and the problem of depositing field emitters on a non-planar surface has prevented the realization of such devices until 2001. We could show that CVD [29] and CACVD [65] allow nanotubes to be grown selectively on rods and wires, as demonstrated by the SEM micrograph of Fig. $6 b$.

CACVD is our preferred method for this application as long wires can be homogeneously covered with nanotube emitters [65]. It is furthermore possible to control the growth and thereby optimize the emission properties (threshold field, emitter density) through the deposition conditions [32] as well as through a careful choice of the catalyst [28][66].

The next step towards a functional device is a fully sealed prototype, which we have very recently realized. The vacuum is maintained by a non-evaporable getter instead of vacuum pumps. The fully sealed tube is shown in Fig. 6c under operation on its portable high voltage power supply. The power supply delivers a fixed $20 \mathrm{~W}$ of power at variable current and voltage, which means that the optimum operating conditions are in the upper third of the $0-7.5 \mathrm{kV}$ range of the power supply (typically $5 \mathrm{kV}$ ). The tube starts instantly and can be continuously dimmed, with good homogeneity and high stability. The cathode emits $\sim 1 \mathrm{~mA} / \mathrm{cm}^{2}$ under the conditions of Fig. $6 \mathrm{c}$ while carbon nanotube cathodes can sustain values that are at least one order of magnitude higher [55]. Our device can therefore reach far higher emitted intensities than the one shown in Fig. 6c. Let us mention also that the deposition of the emitters is carried out as the last step before tube sealing, which is a crucial advantage for a production process and cannot be realized with usual CVD techniques. 

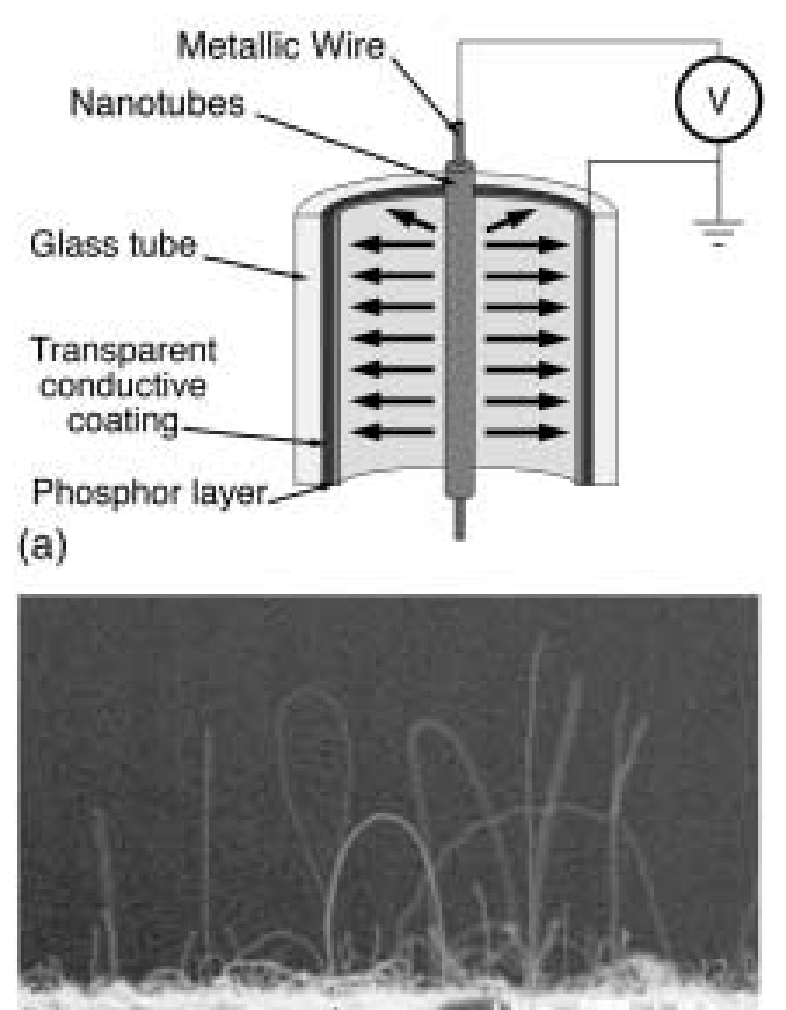

(b)

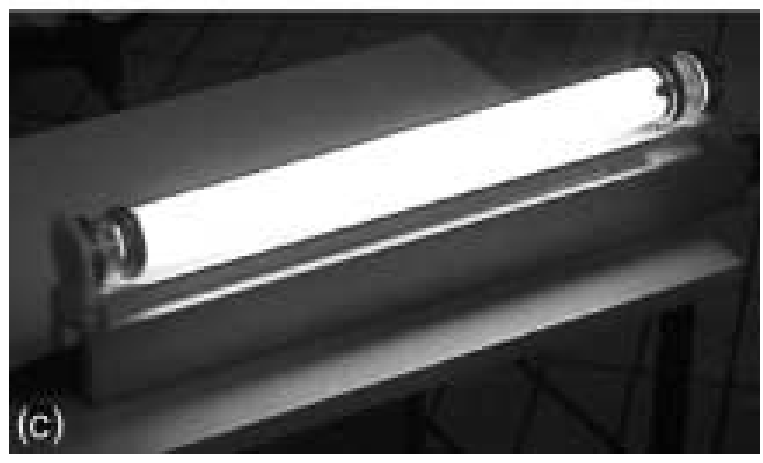

Fig. 6. (a) Schematic principle of a luminescent tube based on field emission. (b) Scanning electron micrograph (SEM) of a carbon nanotube film grown directly by CVD on a metallic wire. (c) Fully sealed cold cathode luminescent tube during operation on its portable power supply at around $5 \mathrm{kV}$ and $4 \mathrm{~mA}$ total current, corresponding to a current density of $1 \mathrm{~mA} / \mathrm{cm}^{2}$ on the cathode.

\section{Conclusion}

Carbon nanotubes are currently under consideration for a variety of applications. We have demonstrated here that MWNTs grown by a variety of CVD techniques provide novel approaches for three promising possibilities. Nanotube functionalization allows their assembly into fibers and to tune their chemical reactivity. The realization of composites, where nanotubes are homogeneously coated with a thin layer of alumina, silica or titania, opens the door for the production of nanoscale materials with novel optical and electronic properties. Finally, nanotubes can be directly deposited on long wires that function as electron-emitting cathodes in mercury-free luminescent tubes.

\section{Acknowledgements}

We thank heartily the Centre Interdépartemental de Microscopie Electronique of EPFL for access to electron microscopes and technical support. Part of the research was supported by the Swiss National Science Foundation, the TMR network of the European Community 'Nanocomp', the Federal Office for Education and Science of Switzerland and the TopNANO21 program.

Received: September 2, 2001
[1] M. Dresselhaus, G. Dresselhaus, P. Avouris, 'Carbon Nanotubes', Springer Press, Berlin, 2000.

[2] P.L. Walker, J.F. Rakszawski, G.R. Imperial, J. Phys. Chem. 1959, 63, 133.

[3] A. Oberlin, M. Endo, J. Crystal Growth 1976, 94, 834

[4] G.G. Tibbetts, J. Crystal Growth 1984, 66, 632.

[5] M. José-Yacaman, M. Miki-Yoshida, L. Rendon, J.G. Santiesteban, Appl. Phys. Lett. 1993, 62, 657.

[6] M. Endo, K. Takeuchi, S. Igarashi, K. Kobori, M. Shiraishi, H.W. Kroto, J. Physics and Chemistry of Solids 1993, 54(12), 1841.

[7] J. Kong, A.M. Cassell, H. Dai, Chem. Phys. Lett. 1998, 292, 567.

[8] P. Nikolaev, M.J. Bronikowski, K. Bradley, F. Rohmund, D.T. Colbert, K.A. Smith, R.E. Smalley, Chem. Phys. Lett. 1999, 313, 91.

[9] V. Ivanov, J.B. Nagy, P. Lambin, A. Lucas, X.B. Zhang, X.F. Zhang, D. Bernaerts, G.V. Tendeloo, S. Amelinckx, J.V. Landuyt, Chem. Phys. Lett. 1994, 223(4), 329.

[10] K. Hernadi, A. Fonseca, J.B. Nagy, D. Bernaerts, J. Riga, A. Lucas, Syn. Met. 1996, 77, 31 .

[11] A. Fonseca, K. Hernadi, P. Piedigrosso, J.F. Colomer, K. Mukhopadhyay, R. Doome, S. Lazarescu, L.P. Biro, P. Lambin, P.A. Thiry, D. Bernaerts, J.B. Nagy, Appl. Phys. A 1998, 67(1), 11.

[12] S. Fan, M.G. Chapline, N.R. Franklin, T.W. Tombler, A.M. Cassell, H. Dai, Science 1999, 283(5401), 512. 
[13] C.J. Lee, D.W. Kim, T.J. Lee, Y.C. Choi, Y.S. Park, Y H. Lee, W.B. Choi, N.S. Lee, G.S. Park, J.M. Kim, Chem. Phys. Lett. 1999, 312, 461 .

[14] H. Araki, H. Kajii, K. Yoshino, Jap. J. Appl. Phys. 1999, 38, L836.

[15] H. Kind, J.-M. Bonard, C. Emmenegger, L.-O. Nilsson, K. Hernadi, E. MaillardSchaller, L. Schlapbach, L. Forró, K. Kern, Adv. Mater. 1999, 11, 1285.

[16] Y.C. Choi, D.J. Bae, Y.H. Lee, B.S. Lee, I.T. Han, W.B. Choi, N.S. Lee, J.M. Kim, Syn. Met. 2000, 108, 159.

[17] Z.F. Ren, Z.P. Huang, J.W. Xu, J.H. Wang, P. Bush, M.P. Siegal, P.N. Provencio, Science 1998, 282(5391), 1105.

[18] H. Murakami, M. Hirakawa, C. Tanaka, H. Yamakawa, Appl. Phys. Lett. 2000, 76(13), 1776.

[19] A.M. Bonnot, M.N. Semeria, J.F. Boronat, T. Fournier, L. Pontonnier, Diamond and Related Materials 2000, 9, 852.

[20] Z.P. Huang, J.W. Xu, Z.F. Ren, J.H.Wang, M.P. Siegal, P.N. Provencio, Appl. Phys. Lett. 1998, 73(26), 3845.

[21] Y. Chen, D.T. Shaw, L. Guo, Appl. Phys. Lett. 2000, 76(17), 2469.

[22] H. Kind, J.-M. Bonard, L. Forró, K. Kern, K. Hernadi, L.-O. Nilsson, L. Schlapbach, Langmuir 2000, 16, 6877.

[23] A. Kumar, G.M. Whitesides, Appl. Phys. Lett. 1993, 63(14), 2002.

[24] A.M. Cassell, J.A. Raymakers, J. Kong, H. Dai, J. Physical Chemistry B 1999, 103(31), 6484.

[25] B.F. Coll, K. Dean, Y. Wei, J. Jaskie, J.-M. Bonard, Appl. Phys. Lett. 2002, submitted.

[26] J.-M. Bonard, K.A. Dean, B.F. Coll, Nano Lett. 2002, submitted.

[27] J.-M. Bonard, K.A. Dean, B.F. Coll, Nano Lett. 2002, submitted.

[28] J.-M. Bonard, P. Chauvin, C. Klinke, Nano Lett. 2002, 2, 665.

[29] J.-M. Bonard, T. Stöckli, O. Noury, A. Chatelain, Appl. Phys. Lett. 2001, 78(17), 2775.

[30] O. Noury, M. Croci, T. Stöckli, A. Chatelain, J.-M. Bonard, Chem. Phys. Lett. 2001, 346, 349.

[31] NanoLight International Ltd., patent pending.

[32] M. Croci, I. Arfaoui, T. Stöckli, A. Chatelain, J.-M. Bonard, Microelectronic J. 2002, submitted.

[33] B. Vigolo, A. Penicaud, C. Coulon, C. Sauder, R. Pailler, C. Journet, P. Bernier, P. Poulin, Science 2000, 290, 1331.

[34] A. Hirsch, Top. Curr. Chem. 1999, 199, 1.

[35] A. Hirsch, Angew. Chem. Int. Ed. 2002, $41,1853$.

[36] M.S. Stark, J. Am. Chem. Soc. 2000, 122, 4162.

[37] M. Dresselhaus, G. Dresselhaus, K. Sugihara, I. Spain, H. Goldberg, 'Graphite Fibers and Filaments, Springer Verlag, Berlin, 1988.

[38] J. Wood, Q. Zhao, M. Frogley, E. Meurs, A. Prins, T. Peijs, D. Dunstan, H. Wagner, Phys Rev B 2000, 62, 7571.

[39] A. Weidenkaff, S. Ebbinghaus, T. Lippert, Chem. Mater. 2002, 14, 1797.

[40] J. Sakamoto, B. Dunn, J. Electrochem. Soc. 2000, 149, A26.
[41] C. Pirlot, I. Willems, A. Fonseca, J. Nagy, J. Delhalle, J. Adv. Eng. Mater. 2002, 4, 109.

[42] J. Fan, M. Wan, D. Zhu, B. Chang, Z. Pan, S. Xie, Synth. Metals 1999, 102, 1266.

[43] X. Gong, J. Liu, S. Baskaran, R. Voise, J. Young, Chem. Mater. 2000, 12, 1049.

[44] L. Schadler, S. Giannaris, P. Ajayan, Appl. Phys. Lett. 1998, 73, 3842.

[45] M. Shaffer, A. Windle, Adv. Mater. 1999, $11,937$.

[46] R. Haggenmueller, H. Gommans, A. Rinzler, J. Fischer, K. Winey, Chem. Phys. Lett. 2000, 330, 219.

[47] E. Flahaut, A. Peigney, C. Laurent, C. Marliere, F. Chastel, A. Rousset, Acta Mater. 2000, 48, 3803.

[48] E. Flahaut, A. Peigney, C. Laurent, A. Rousset, J. Mater. Chem. 2000, 10, 249.

[49] S. Banerjee, S. Wong, Nano Lett. 2002, 2, 195.

[50] V. Gavalas, R. Andrews, D. Bhattacharyya, L. Bachas, Nano Lett. 2001, 1 , 719.

[51] T. Kuzumaki, O. Ujiie, H. Ichinose, K. Ito, Adv. Eng. Mater. 2000, 2, 416.

[52] K. Hernadi, E. Ljubovic, J. Seo, L. Forró Adv. Mater. 2002, submitted.

[53] K. Hernadi, E. Ljubovic, J. Seo, L. Forró Adv. Mater. 2002, submitted.

[54] E. Ljubovic, K. Hernadi, L. Thien-Nga, L. Forró, Chem. Mater. 2002, submitted.

[55] J.-M. Bonard, H. Kind, T. Stöckli, L.-O. Nilsson, Solid State Electronics 2001, 45, 893.

[56] A.G. Rinzler, J.H. Hafner, P. Nikolaev, L. Lou, S. G. Kim, D. Tomanek, P. Nordlander, D.T. Colbert, R.E. Smalley, Science 1995, 269(5230), 1550.

[57] W.A.D. Heer, A. Chatelain, D. Ugarte, Science 1995, 270(5239), 1179.

[58] H.-W. Fink, W. Stocker, H. Schmid, Phys. Rev. Lett. 1990, 56, 1204.

[59] See also http://www.itron-ise.co.jp/english/nano/index.htm.

[60] R. Rosen, W. Simendinger, C. Debbault, H. Shimoda, L. Fleming, B. Stoner, O. Zhou, Appl. Phys. Lett. 2000, 76(13), 1663.

[61] O. Zhou's group (UNC Chapel Hill) and W. Zhu (Lucent Technologies), pending U.S. patents.

[62] Q.H. Wang, A.A. Setlur, J.M. Lauerhaas, J.Y. Dai, E.W. Seelig, R.P.H. Chang, Appl. Phys. Lett. 1998, 72(22), 2912.

[63] J.M. Kim, N.S. Lee, W.B. Choi, J.E. Jung, I.T. Han, D.S. Jung, S.H. Park, S.S. Hong, H.Y. Kim, presented at the 14th Internation Winterschool on Electronic Properties of Novel Materials (IWEPNM2000), Kirchberg (Austria), 4-11.3.2000.

[64] See also http://www.oxinst.com/ ANLNWP390.htm.

[65] M. Croci, J.-M. Bonard, O. Noury, T. Stöckli, A. Chatelain, Adv. Mater. CVD 2002, 8, 89 .

[66] J.-M. Bonard, N. Weiss, H. Kind, T. Stöckli, L. Forró, K. Kern, A. Chatelain, $A d v$. Mater. 2001, 13, 184 